\title{
APROXIMACION AL ESTUDIO DE LA ALCALDIA A TRAVES DE SU EVOLUCION LEGISLATIVA.
}

\author{
Por \\ Cristóbal Guirado Cid \\ Doctor en Derecho. Técnico de la Administración Local. \\ A los Profs. L. Martín-Retortillo, Sosa Wagner, Parejo Alfonso, \\ Martínez Marín, Guillamón Alvarez y López Pellicer.
}

SUMARIO: 1. INTROdUCCION. CONEXION AlCALDE CONSTITUCIONAL/AlCALDE ORdinario del antiguo régimen. 2. Modelo doceañista. 3. Modelo liberal. 4.

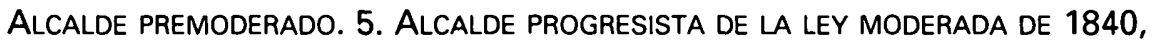
Modificada POR DeCreto de 1843. 6. Modelo MOderado. 7. Modelo progreSISTA DE LA LEY DE 1856. 8. MODELO SURGIDO DE LA REVOLUCION DE 1868: EL Alcalde de la ley de 1870. 9. El Alcalde de la Restauracion. 10. El Alcalde del Estatuto Municipal. 11. El Alcalde republicano. 12. El Alcalde franguista. 13 El AlCALDE de la transicion POLITICA. 14. Modelos diferenCIADOS. 15. El ALCALDE ACTUAL.

\section{INTRODUCCION. CONEXION ALCALDE CONSTITUCIONAL/AL- CALDE ORDINARIO DEL ANTIGUO REGIMEN.}

El estudio de la institución de la Alcaldía a través de nuestra legislación lleva a tres conclusiones que a priori dejamos ya enunciadas: $1 \stackrel{\circ}{\circ}$, la Alcaldia no es una institución estática; $2^{\circ}$, en su sentido actual se configura a través de una sucesión de disposiciones a partir de la Constitución de Cádiz; 3o el modelo gaditano es el resultado de dos fuerzas concurrentes, la que está representada por la tradición, que no se interrumpe, y la constituida por los ideales liberales inspiradores de la Revolución Francesa, en la medida que fueron recogidos por la Constitución (1).

(1) Como ha destacado PAREJO ALFONSO, la Constitución no es fruto de una corriente o pensamiento ideológico único. Por eso no son válidas, en este punto, las posturas maximalistas tanto la que ve en la Constitución una pura continuidad con el pasado, como la que afirma su carácter de ruptura con el mismo y la absoluta asimilación de los postulados revolucionarios (PAREJO ALFONSO, L. : "La Región y la legislación histórica de régimen local"; en "Las autonomías regionales. Aspectos políticos y jurídicos"; Presidencia del Gobierno; Madrid, 1977; pp. 21 y 22). VV. también CARRASCO CANALS, C. : "El municipio en la Administración Española en el siglo XIX"; Revista de Estudios de Administración Local; núm. 173, 1972; p. 74; BERMEJO GIRONES, J. I. : "Aportaciones al Derecho Municipal" ; Reus; Madrid, 1985; p. 5; y ARROYO VILLANOVA, A. : "Elementos de Derecho Administrativo"; Tomo I; Santarén; Valladolid, 1955; p. 268. 
Sin desconocer, por ello, que el Alcalde actual hunde sus raíces en el antiguo régimen es válido tomar como punto de partida para el estudio de esta magistratura la Constitución de 1812, que marca el inicio de una nueva concepción de la organización política del Estado, determinada básicamente por la introducción del dogma de la separación de poderes. La conexión del Alcalde constitucional de 1812 con el Alcalde ordinario de régimen absoluto es, sin embargo, indudable. Confirman esta parcial identificación el Decreto de las Cortes LXXXII, de 6 de agosto de 1811, sobre incorporación a la Nación de los señoríos jurisdiccionales, donde se suprimen los Alcaldes Mayores y se dejan subsistentes los Ayuntamientos y los Alcaldes Ordinarios (2); la Orden de 1 de julio de 1812, sobre anulación de los nombramientos municipales efectuados por vía gubernativa, para dejar "expeditos a los pueblos para que nombren sus Alcaldes ordinarios"; el Reglamento de Audiencias y Juzgados de primera instancia, aprobado por Decreto $\mathrm{CCl}$, de 9 de octubre de 1812, en donde, con referencia a las competencias no judiciales, se señala que "ejercerán los Alcaldes la jurisdicción y facultades que han tenido, hasta ahora, los Alcaldes ordinarios, arreglándose siempre a lo dispuesto en la Constitución" (3); y, finalmente, la Real Cédula de 30 de julio de 1814, dictada durante la primera reacción absolutista de Fernando VII, que preceptúa textualmente: "quedan extinguidos los oficios de los Alcaldes ordinarios, que antes se decían constitucionales" (4).

Pero el Alcalde doceañista ha de evolucionar profundamente hasta llegar al modelo actual. Seguir esa trayectoria, siquiera sea sucintamente, es objeto de este trabajo.

Un análisis en profundidad de nuestro Derecho patrio nos muestra cómo, partiendo de Cádiz y a través de las grandes leyes de régimen local, se va trazando una línea de evolución continua de la Alcaldia, por encima de sistemas y concepciones políticas y por encima de los alternativos periodos de vigencia de que han disfrutado algunos de estos textos: el Alcalde sigue una trayectoria imparable y prácticamente sin fisuras, desde ser básicamente un órgano judicial y al propio tiempo representativo del poder central en el municipio a ser un órgano político-administrativo netamente local, cada vez más definido.

(2) Apartado III del Decreto de las Cortes de Cádiz LXXXII, de 6 de agosto de 1811.

(3) Artículo III del Capitulo IV del Decreto de las Cortes de Cádiz $\mathrm{CCl}$, de 9 de Octubre de 1812.

(4) Todavia la Ley Municipal de 8 de enero de 1845 habla de "Alcalde ordinario" por contraste con el "Alcalde corregidor", posibilidad prevista en dicho texto. 
Pero, junto a esta trayectoria, la Alcaldía a lo largo de su historia se ve sometida a una fuerte tensión propiciada por dos fuerzas políticas de signo contrario, que pueden detectarse en toda su significación en los procesos de elaboración de las distintas leyes: la que propende el sometimiento de los Ayuntamientos al Poder del Estado, en nombre del orden y de la salvaguarda de los intereses generales; y la que demanda libertades y potestades para la organización municipal. Ello explica el sentido pendular de nuestra legislación de régimen local.

Si la primera trayectoria se presenta rectilínea, esta segunda adoptaría evidentemente el perfil de una línea quebrada. Las interconexiones de una y otra van determinando diversos modelos de Alcalde, que vienen a coincidir sustancialmente con los grandes textos de Régimen Local a que antes nos hemos referido.

\section{MODELO DOCEAÑISTA.}

De esta forma puede hablarse de un primer modelo, el gaditano, dentro del cual distinguimos, a su vez, entre un Alcalde doceañista, definido por la propia Constitución de 1812 y por la legislación emanada directamente de las propias Cortes de Cádiz; y un Alcalde liberal -muy próximo al Alcalde progresista-, que delimita fundamentalmente -dentro del mismo marco constitucional- la Instrucción de 1823.

Ya hemos aludido a que el Código de Cádiz introduce el principio de la separación de poderes. Sin embargo, en el Alcalde persisten excepcionalmente las facultades judiciales junto a las político-administrativas. Esta circunstancia pone ya de relieve la dificultad de establecer cambios profundos en las estructuras locales -que se evidenciará también en otros momentos de la evolución de la Alcaldía-.

Pero no obstante esta permanencia en el Alcalde de facultades judiciales, la idea de la justicia con el sentido englobador de todo el poder político que tenia en el régimen absoluto -lo que no es realización de la justicia no incumbe al Estado, señala García Gallo (5)- ya no es posible mantenerla. Por ello no aceptamos la tesis que sigue viendo en el Alcalde doceañista a un órgano esencialmente jurisdiccional (6). Tampoco la

(5) GARCIA GALLO, A. : "La división de las competencias en España en la Edad Media"; en "Actas del II Symposium de Historia de la Administración"; Instituto de Estudios Administrativos: Madrid, 1971; p. 294.

(6) V. SANTAMARIA PASTOR, J. A. : "Estudio preliminar" a "Tratado de la jurisdicción ordinaria para la dirección y guía de los Alcaldes de los pueblos de España" de VIZCAINO PEREZ, V. ; y a "Dirección teórico-práctica de Alcaldes constitucionales" de MIGUEL SANCHEZ, F. de P. ; Instituto de Estudios de Administración Local; Madrid, 1979; p. 19. 
opinión diametralmente opuesta de que el Alcalde de 1812 queda desjudicializado (7). En este sentido es destacable que los propios legisladores gaditanos desarrollen ampliamente -vía Decreto- las facultades judiciales del Alcalde y no así las político-administrativas (8).

Lo que resulta evidente, sin embargo, es que el principio de separación de poderes fuerza desde su inicio la evolución de la Alcaldía, primero hacia su desjudicialización; $y$, posteriormente, a partir de su carácter político-administrativo, hacia su configuración definitiva de órgano local. Hay que tener muy presente que las facultades que asigna al Alcalde la Constitución de Cádiz en el ámbito administrativo son la de presidir el Ayuntamiento y los actos electorales, en nombre del Jefe Político -antecedente de nuestro Gobernador Civil- y la de guardar el orden y la seguridad ciudadana (9), actuación esta última netamente gubernativa. $Y$ junto a ellas $y$ con el mismo carácter, la presidencia de los actos electorales, con lo que, por otra parte, se inaugura un intervencionismo del ejecutivo municipal en los procesos comiciales de perniciosas consecuencias para la vida local.

$Y$ hacemos un paréntesis para señalar que, aun cuando el Código de Cádiz introduce el principio de pluralidad de Alcaldes, en los Alcaldes distintos del "Primero" hemos de ver necesariamente el antecedente de los que después serán los tenientes de Alcalde, ya que, aunque en aquéllos se parte de un principio de igualdad, hay siempre una prelación en favor del Alcalde primer nombrado, y ello porque el carácter de órgano monocrático de la Alcaldía, como inherente a su propia naturaleza, resulta incompatible con el establecimiento de otras instituciones homólogas en el caso del propio Ayuntamiento.

Aspectos destacables del Alcalde doceañista son también el carácter temporal, gratuito y obligatorio del cargo, al igual que ocurre con los demás oficios concejiles -lo que pone fin a la perpetuidad en los mismos y al mercantilismo de que venían siendo objeto (10)-; y el de

(7) V. GARCIA FERNANDEZ, J.: "El origen del municipio constitucional"; Instituto de Estudios de Administración Local; Madrid, 1983; pp. 247 y 270.

(8) Las facultades judiciales del Alcalde gaditano las desarrolló el Reglamento de las Audiencias y Juzgados de primera instancia, aprobado por Decreto $\mathrm{CCl}$, de 9 de octubre de 1812.

(9) Artículos 309 y 321. $2^{\circ}$ de la Constitución de 1812.

(10) W. MORELL OCAÑA, L. : "La figura del Alcalde desde la Constitución de Cádiz hasta el caonovismo"; Revista Española de Derecho Administrativo"; núm. 33, 1982; p. 168; y "El Régimen Local Español"; Civitas; Madrid, 1988; p. 540. Sobre el proceso de oligarquización de los municipios WV. LAREDO QUESADA, M. : "El poder central y las ciudades en España, del siglo XIV al final del antiguo régimen"; Revista de Administración Pública; núm. 94, 1981; pp. 179-180; DOMINGUEZ ORTIZ, A. : “Sociedad y Estado en el siglo XVIII espanol"; Ariel: Barcelona, 1976; pp. 455 y ss. ; y RODRIGUEZ CASADO, V. : "Las reformas provinciales en la España de Carlos III"; en "Crónica del IV Congreso histórico municipal interamericano"; Instituto de Estudios de Administración Local; Madrid, 1959; pp. 204-215. 
su naturaleza democrática, aun cuando lo sea a través de una elección de segundo grado como el resto de las magistraturas locales y aun cuando el sufragio universal que allí se establece no contemple todavia, por razón del momento cultural, el voto femenino ni, lo que es más sorprendente, el de los españoles de procedencia africana (11). Pero, en todo caso, dicho origen electivo va a suponer un grave atentado al principio de unidad del poder ejecutivo definido en el propio texto constitucional (12), y mantenido durante mucho tiempo como dogma indiscutible. Esta nueva contradicción, aun cuando en este momento se justifica en razón a las facultades judiciales del Alcalde (13), de inmediato se convierte en factor determinante de su vocación localista, que también se ve favorecida por las funciones presidencialistas de la Alcaldía.

Otro dato de interés del Alcalde de Cádiz, que incide con fuerza en esa evolución, está representado por la Milicia Nacional, creada por el propio Código fundamental precisamente como medio para asegurar la independencia de la Nación incluso frente a la propia Corona, y cuya Jefatura local ostentará el Alcalde (14). Como puede advertirse, la Constitución está sentando las bases de la profunda transformación de esta figura.

\section{MODELO LIBERAL.}

1823 es fecha clave en esa evolución. En el Alcalde de la Instrucción de 3 de febrero de dicho año, "para el gobierno económico-político de las provincias" -obra del trienio liberal, transcurrido por tanto el primer periodo de gobierno absolutista de Fernando VII, que supone el retorno al "ancien régime" - no es fácil encontrar una mínima coherencia interna. Ante todo, el desarrollo de las facultades político-administrativas, que realiza esta norma, hace del Alcalde una magistratura claramente representativa del Poder central: es fundamentalmente el garante del orden público (15).

(11) Señala el artículo 22 de la Constitución de 1812 que a "los españoles que, por cualquier linea, sean habidos o reputados de Africa" sólo queda "abierta la puerta de la virtud y del merecimiento para ser ciudadanos".

(12) Ibidem; articulo 170.

(13) V. en este sentido GUIRADO CID, C. : "El Alcalde en la legislación española"; Trivium; Madrid, 1991; pp. 11 y 12.

(14) Sobre la intencionalidad politica que determinó la creación de la Milicia Nacional V. Diario de Sesiones de las Cortes Generales y Extraordinarias núm. 47, 16. 1. $1812 ;$ pp. 2633 y 2636.

(15) VV. en este sentido SANTAMARIA PASTOR, J. A. : "Estudio preliminar ..."; ob. cit. ; p. 20; y PAREJO ALFONSO, L. : “La región ...”; ob. cit. ; p. 49. 
Esta fuerte significación gubernativa supone una indudable incidencia en el antiguo carácter judicial del Alcalde y marca a nuestro juicio el punto de inflexión hacia la desjudicialización de la figura. A partir de aquí se puede afirmar, cada vez con mayor propiedad, que las facultades jurisdiccionales -aunque se mantengan en el Alcalde hasta 1856- permanecen como solución fáctica y entendidas como añadidas a su condición de órgano político-administrativo. La tensión entre las facultades judiciales y las administrativas quiebra así a favor de estas últimas. Por otra parte, aunque el Alcalde preside el Ayuntamiento ya en nombre propio, su presidencia no es preceptiva. Tampoco es necesariamente órgano ejecutivo municipal (16).

Su carácter gubernativo se extrema de tal forma que lleva a esta magistratura a una situación de ambivalencia miembro del Ayuntamiento/órgano independiente del Ayuntamiento de muy difícil comprensión (17). En todo caso, su vocación localista -a partir de su origen electivo y del mando de la milicia nacional- es ya irreversible. EI comportamiento de los Ayuntamiento liberales es testimonial al respecto (18).

\section{ALCALDE PREMODERADO.}

1835 representa otro hito importante. En el marco del Estatuto Real de 1834, el R.D. de 23 de julio del año siguiente, "para el arreglo provisional de los Ayuntamientos del Reino", dado por la Reina Gobernadora María Cristina, superado el segundo y último período de reinado absolutista de Fernando VII, es claramente expresivo de la evolución de la Alcaldía hacia su carácter localista, y ello pese a que la organización municipal que regula este texto es casi periférica del Estado. En este R. D. -y es un dato que sorprende especialmente- se esboza ya el triple carácter del Alcalde -Presidente del Ayuntamiento, Jefe de la Administración Municipal y Delegado del Gobierno- que ha

(16) Como puede deducirse de los articulos 2, 80, 216, 217 y 219 de la Instrucción de 3 de febrero de 1823.

(17) El binomio Alcalde/Ayuntamiento se resuelve en definitiva, en la Instrucción de 1823 , en una relación de mutuo auxilio y colaboración recíproca. $V$. al respecto GUIRADO CID, C.: ob. cit. ; pp. 41 y 42.

(18) VV. SEVILLA ANDRES, D. : "Centralización"; Revista de Estudios de la vida local; núm. 185, 1975; p. 18; y NIETO, A. : "Obra juridico-administrativa de Ortiz de Zún̄iga"; estudio preliminar a "El libro de los Alcaldes y Ayuntamientos" de ORTIZ DE ZUGIÑA, M. ; Instituto de Estudios de Administración Local"; Madrid, 1978; p. XXXVI; y LOPEZ RAMON, F. : "La caracterización juridica de las fuerzas armadas"; Centro de Estudios Constitucionales; Madrid, 1987; p. 65. 
venido definiéndolo tradicionalmente. Hay también un fugaz intento de liberar al Alcalde de las poblaciones más importantes de sus facultades judiciales.

Es un modelo de Alcalde que bien puede llamarse "Premoderado", al que definen otros tres datos fundamentalmente: su designación se produce por el sistema de las dos confianzas, a partir de una elección que es ya directa, aunque censitaria, la cual hace de la propiedad $y$, en menor grado, de la cultura requisito de capacidad para el derecho de sufragio; criterio que constituirá una constante a lo largo de casi todo el siglo XIX (19). Paralelamente, persiste tímidamente en el Alcalde el mando de la Milicia Nacional y se introducen abiertamente los sistemas de suspensión y destitución gubernativas de los miembros del Ayuntamiento. La Alcaldía finalmente se hace única, derivando los Alcaldes subalternos hacia la nueva figura, ya citada, del Teniente de Alcalde.

\section{ALCALDE PROGRESISTA DE LA LEY MODERADA DE 1840, MODI- FICADA POR DECRETO DE 1843.}

La lucha entre progresistas y moderados, que es sin duda uno de los acontecimientos políticos más significativos del siglo XIX, tiene una especial repercusión en la concepción de la Administración Local y, muy singularmente, de la Alcaldía. Los criterios definidores de una y otra ideología son claros y precisos: para el progresismo el Alcalde es órgano representativo de la ciudadanía; para el moderantismo lo es esencialmente del poder ejecutivo del Estado. En su consecuencia, para los primeros el Alcalde debe ser de origen electivo; por los moderados se postula la fórmula de las dos confianzas: al Poder central le corresponde designar al Alcalde entre los Concejales, elegidos previamente por el electorado. De esta forma, el sistema de erección del Alcalde se convierte en signo esencialmente distintivo de los respectivos modelos. EI propio JAVIER DE BURGOS aludirá a la designación mixta del Alcalde como "una doctrina que... ha marcado la línea separatoria entre nuestros partidos políticos" (20).

(19) El sufragio censitario parte de la doctrina fisiocrática que, en el pensamiento de TURGOT, vinculaba el derecho de ciudadania a la posesión de riqueza inmueble. GARCIA DE ENTERRIA comenta al respecto que "si TURGOT se detuvo en la propiedad inmueble, ello fue debido, más que a dogmas de escuela, a la época misma en que escribe... anterior a la revolución industrial" (GARCIA DE ENTERRIA, E.: "Turgot y los origenes del municipalismo moderno"; Revista de Administración Pública; núm. 33, 1960; p. 95).

(20) BURGOS Y OLMO, J. F. DE: Conferencia sobre "Ideas de Administración", publicada en el periódico "La Alhambra" del Liceo de Granada; núm. 7, 14. 2. 1841. V. en el mismo sentido GARCIA FERNANDEZ, J. :Ob. cit. ; p. 318. También SEVILLA ANDRES, D. : Ob. cit. ; p. 22; y CASTRO, C. DE: "La revolución liberal y los municipios españoles"; Alianza; Madrid, 1979; p. 126. 
Los argumentos en apoyo de una y otra tesis son absolutamente prolijos dando lugar a densos debates parlamentarios sobre el tema, en los que está ausente la más mínima voluntad de acercamiento (21) El artículo 70 de la Constitución de 1837, aunque proclama claramente el origen electivo de los Ayuntamientos, no resuelve el problema, dada la separación doctrinaria que mantiene el progresismo entre Alcalde y Ayuntamiento. Pero es lo cierto que esa sutil distinción se mueve exclusivamente en el terreno de los intereses politicos del Gobierno: mediante la designación del Alcalde se persigue la dominación de los Ayuntamientos por el Poder central a través de su Alcaldía y la utilización de ésta como instrumento al servicio del Gobierno en los procesos electorales, como ha puesto de relieve MARTINEZ MARIN (22).

Paralelamente y aun cuando ambas tendencias mantienen un criterio unánime en el rechazo del sufragio universal -"palabra alarmante y revolucionaria" en expresión del progresista ARGUELLES (23)-, existen indudables diferencias en cuanto a la extensión de la base electoral censitaria. Asimismo, el mantenimiento de la Milicia Nacional, la mayor seguridad en el ejercicio de los cargos concejiles y el control de los Ayuntamientos a través de la Diputación Provincial, en detrimento de las facultades del Gobierno Civil, marcan otras diferencias entre progresistas y moderados, como ha destacado SOSA WAGNER (24).

La Ley Municipal de 1840 representa un intento de conciliación de ambas posiciones. Es una ley moderada con algunas concesiones al progresismo pero que sigue fiel al pensamiento moderado en el punto irreconciliable referido a la designación del Alcalde, lo que coadyuva decididamente al desencadenamiento de la revolución progresista de 1840, que provoca la caída de la Reina Gobernadora y su sustitución por la Regencia de Espartero. La puesta en vigor de la Ley sólo será posible cuando tres años más tarde se restablezca el sistema de elección del Alcalde (25).

(21) V. Diario de Sesiones del Congreso núms. 42 a 54; 71 a 75 y 86 a 89 ; período comprendido entre 13.4 a 4.6. 1840. Destacables son las intervenciones de ARGUELLES, entre los progresistas, y de MARTINEZ DE LA ROSA, entre los moderados.

(22) MARTINEZ MARIN, A. : “La representatividad municipal española. Historia legislativa y régimen vigente"; Secretariado de Publicaciones de la Universidad de Murcia; 1989; p. 53.

(23) Diario de Sesiones del Congreso; núm. 69, 14. 5. 1840; p. 1659.

(24) SOSA WAGNER, F. : "Manual de Derecho Local", Tecnos; Madrid, 1987; p. 38. V. también TUÑNON DE LARA, M. ; "Historia de España"; Tomo VIII : "Revolución burgesa, oligarquia y constitucionalismo"; Labor; Madrid, 1983; pp. 178-183.

(25) La Ley de 1840 se pone en vigor, con modificación de sus articulos $31,35,45$, 49 y 76 , por Decreto de 30 de diciembre de 1843. 
Pero lo que interesa destacar es que, por encima de disquisiciones doctrinales, el Alcalde se consolida definitivamente en este texto como órgano local; es prioritariamente el "administrador del pueblo" en la propia terminologia de la Ley. Desde este inequívoco carácter local se asigna a la Alcaldía una delegación especifica de competencias gubernativas, que serán a partir de ahora una atribución añadida a su definitiva condición de gestor de los intereses vecinales, mantenida por razones económicas y de oportunidad política pero claramente separable, sin que la supresión de la misma desnaturalice la institución. Por ello es ya posible hablar con toda propiedad del triple carácter del Alcalde antes aludido.

\section{MODELO MODERADO.}

La ley de 1845 , moderada por excelencia, mantiene con total rotundidad la distinción doctrinaria entre el Alcalde y el Ayuntamiento, que posibilita ya de forma incuestionable el artículo 73 de la nueva Constitución de ese mismo año, abriendo la vía para la designación del Alcalde por el sistema de las dos confianzas; $y$ es fiel a todos los postulados del moderantismo. La base electoral censitaria llega a su momento de máxima restricción, el mando de la Milicia Nacional se elimina -poco antes había sido creada la Guardia Civil como réplica moderada a la Milicia (26)-, y el dependentismo de los Ayuntamientos, y sobre todo de la Alcaldía, respecto del Gobernador Civil, se agudiza especialmente mediante los institutos de la suspensión y la destitución y la mayor intervención gubernativa en la vida local, y, evidentemente también, en los procesos electorales. La centralización llega ahora a uno de sus momentos más álgidos, como ha señalado PAREJO ALFONSO (27). El Alcalde definido por esta Ley responde asi a un modelo netamente moderado.

Sin embargo, y contra lo que pudiera pensarse, se potencian en este texto sus facultades administradoras: el Alcalde representa ya al pueblo o distrito municipal como actor y como demandado, facultad que venía siendo desempeñada por el Procurador Síndico. Esta figura (que también deja de tener aquí carácter diferenciado respecto del cargo de Regidor) ha supuesto, sobre todo en función de su arraigo y de sus antecedentes democráticos -estudiados por GUILLAMON ALVAREZ (28)-, un grave obstáculo en el camino de la Alcaldia hacia su

(26) En 1844 se producen los Decretos fundacionales de la Guardia Civil, el primero, de 28 de marzo, que no llegó a regir, y el segundo y definitivo, de 13 de mayo.

(27) PAREJO ALFONSO, l. : Ob. cit. ; p. 70.

(28) GUILLAMON ALVAREZ, F. J. : "Las reformas de la Administración Local durante el reinado de Carlos III"; Instituto de Estudios de Administración Local; Madrid, 1980. 
configuración definitiva. Por otra parte, el Alcalde sólo es responsable del orden público en las localidades donde no exista delegado del gobierno, lo que representa ya un criterio diametralmente opuesto a la concepción que de la Alcaldía tenían la Constitución de Cádiz y la Instrucción de 1823, según hemos analizado.

\section{MODELO PROGRESISTA DE LA LEY DE 1856.}

Al modelo moderado de la ley de 1845 seguirá el progresista de la de 1856. La ley de Ayuntamientos de 5 de julio de este último año, aprobada durante el llamado bienio progresista, es en rigor la única Ley municipal elaborada por unas Cortes que respondian con exclusividad a esta ideología. Sin embargo, la falta de uniformidad de criterio en el seno de las mismas hace que la Ley se sitúe a mitad de camino entre la de 1823 -cuya inviabilidad se afirmaria por el Ministro PATRICIO DE LA ESCOSURA (29)- y la de 1845, extremos liberal y moderado respectivamente.

Los rasgos definidores del Ayuntamiento y de la Alcaldía diseñados por este texto hay que buscarlos en la mayor extensión de la base electoral; en un cierto grado de independencia en el desenvolvimiento del ámbito de gestión atribuido a las municipalidades; en un mayor protagonismo de la Diputación Provincial; en el resurgimiento, ya absolutamente fugaz, de la Milicia Nacional; y en las mayores garantías de permanencia en los cargos concejiles: la destitución ha de ser siempre por decisión judicial y la disolución de todo un Ayuntamiento corresponde al Parlamento. $Y$, obviamente, en la provisión electoral de todas las magistraturas locales que, sin duda, sigue representando el dato más definidor del modelo.

Doctrinariamente el Alcalde vuelve a ser miembro integrante del Ayuntamiento. Sin embargo, el proceso evolutivo de la Alcaldía en algún aspecto experimenta un leve retroceso por la inevitable propensión de retorno al pasado liberal. Expresión de ello es la vuelta al sistema de pluralidad de Alcaldes -aunque esto quede reducido en la práctica a una cuestión meramente semántica- y el fortalecimiento de la institución del Síndico encarnada ahora en uno de los Regidores, al no poderse restablecer el cargo, con carácter diferenciado al de estos últimos, por motivos puramente constitucionales. Dato positivo, por el contrario, es que el Alcalde no preside ya el acto electoral y destacable es también la falta de unanimidad en las Cortes respecto del tradicional carácter obligatorio de los cargos concejiles (30).

(29) Diario de Sesiones del Congreso; núm. 330, 6. 3. 1856: p. 11.368.

(30) Ibidem; núm. 333, 10. 3. 1856; pp. 11.520 y 21. 
Resulta, sin embargo, oportuno resaltar la escasa efectividad de la obra legislativa del bienio, en especial de la Constitución de 1856, que no llega a publicarse, y de la propia ley Municipal, que es derogada ese mismo año.

Es el momento también en que el dogma de la separación de poderes alcanza su plena virtualidad: casi paralelamente a la publicación de la Ley de Ayuntamientos el Alcalde pierde definitivamente sus seculares facultades judiciales que pasan a los recién creados Jueces de $\mathrm{Paz}$ (31). E igualmente las militares, dado que la Milicia $\mathrm{Na}$ cional se disuelve y extingue en el propio año 1856 (32).

\section{MODELO SURGIDO DE LA REVOLUCION DE 1868: EL ALCALDE DE LA LEY DE 1870.}

El Alcalde que delimitan las Leyes Municipal de 1870 y electoral del mismo año, producto ambas de la Revolución de 1868 -que supuso el derrocamiento de Isabel II y el establecimiento del gobierno provisional del General Serrano- quiere ser expresión de los ideales conquistados en dicha revolución. De esta forma, el dato más definidor de las mismas está representado por el establecimiento del sufragio universal masculino para la elección de los Ayuntamientos, pero que aqui tiene el importante contrapeso de la Asamblea de Vocales Asociados que sigue representando los intereses de los contribuyentes, con lo que para CASTELAR se creaba una oligarquía junto al sufragio universal (33); representando una fórmula de compromiso entre el sufragio universal y el censitario y constituyendo una nueva prueba de la dificultad que implica la modificación de las instituciones a nivel de comunidad municipal.

El criterio electivo se hace extensivo al Alcalde, si bien a través, por primera vez, de una elección indirecta -elección por la Corporación de entre sus miembros-, $y$ además se le sigue garantizando su persistencia en el cargo del que sólo puede ser removido por vía judicial.

El Alcalde es asimismo representante del Ayuntamiento en todas las cuestiones que no correspondan al Síndico. De otro lado, la atribución

(31) Los Juzgados de Paz se crean por el Real Decreto de 22 de octubre de 1855, que ordena poner en ellos Jueces de Paz. $Y$, aunque la Real Orden de 2. 1. 1856 dispone queden en suspenso tales nombramientos, el Real Decreto de 28 de noviembre del mismo año deja sin efecto esta última disposición, con lo que termina definitivamente el ejercicio por los Alcaldes de sus seculares facultades judiciales.

(32) La Milicia Nacional se disuelve y extingue por Real Decreto de 15 de agosto de 1856.

(33) Diario de Sesiones del Congreso; núm. 278, 11. 5. 1870; p. 7885. 
al primer magistrado local de facultades delegadas o representativas del Poder Central encontró ya una fuerte oposición por parte del ala menos conservadora del Congreso (34). Se vuelve al sistema de Alcalde único, pasando definitivamente los Alcaldes subalternos a la condición de Tenientes de Alcalde y, por primera vez, se asigna al primer magistrado local gastos de representación, lo que inicia el camino hacia el carácter remunerado de los cargos concejiles.

\section{EL ALCALDE DE LA RESTAURACION.}

La restauración de la monarquia en la persona de Alfonso XII supone, contrariamente, para la Administración Local un claro retroceso de signo reaccionario y centralizador, que se materializa en la reforma introducida en la anterior Ley Municipal por la de 1876, de acuerdo con la Constitución del mismo año, y que da lugar a la ley refundida de 1877; por más que la reforma se presente -por el Ministro ROMERO Y ROBLEDO- como solución transaccional y conciliadora y de orientación liberal-conservadora (35). La ley de 1877, por otra parte, no aporta nada al proceso evolutivo de la Alcaldía por su sentido de mera modificación, en aspectos muy concretos, de la legalidad anterior.

Desde otro ámbito de consideración, si es importante destacar que la reforma tiene una intencionalidad política muy precisa en dos cuestiones fundamentales: supresión del sufragio universal (36) -con la consiguiente reducción del número de miembros de la Asamblea de Vocales Asociados, como órgano ya innecesario- y control gubernamental de los Ayuntamientos a través de sus Alcaldes, designados de nuevo por el sistema de las dos confianzas, que se ve apoyado ahora por la doctrina administrativista de la época -MELLADO, SANTAMARIA DE PAREDES, etc. (37)-; suponiendo la Ley, en rigor, una vuelta a la moderada de 1845 .

(34) Ibidem; núm. 282, 16. 5. 1870; p. 8010.

(35) Ibidem; núm. 124, 16. 11. 1976; p. 3491.

(36) Aunque la vuelta al sufragio universal activo se produce con la Ley Electoral de 1890 y al pasivo con la de 1907, hay que anotar que el primero de estos textos ofrece el dato absolutamente negativo de hacer al Alcalde nuevamente presidente de las mesas electorales, to que dará lugar a un período de total corrupción de los procesos comiciales. Este criterio se corrige en la Ley de 1907.

(37) VV. MELLADO, F. : "Tratado elemental de Derecho Administrativo"; Madrid, 1899; p. 207; y SANTAMARIA DE PAREDES, V. : "Curso de Derecho Administrativo según sus principios generales y la legislación actual de España": Madrid, 1914; pp. 195 y 197. 
El largo periodo de su vigencia se explica por la dificultad de conseguirse su sustitución a partir de la inestabilidad de los gobiernos. Mas de veinte proyectos de reforma son, sin embargo, suficientemente expresivos del clima absolutamente favorable a su derogación.

La limitación de las municipalidades a un cuadro de competencias tasadas y el sentido uniformista y centralizador con que, en mayor o menor medida, se había entendido hasta aquí a la Administración Municipal contrastan con toda la corriente regeneracionista que surge en nuestro País a partir del desastre militar del 98, y que está en la base de la mayoría de los proyectos reformistas.

\section{EL ALCALDE DEL ESTATUTO MUNICIPAL.}

$Y$ resulta paradójico que haya de ser en el seno de un sistema político netamente centralizador -la Dictadura de Primo de Rivera- cuando, a través del Estatuto Municipal de 1924, se recoja el espíritu renovador de aquellos proyectos -fundamentalmente de los de Maura de 1903 y 1907- y se inaugure una nueva concepción de la Administración Local caracterizada por el reconocimiento de la heterogeneidad $y$ la autonomía municipal y, como consecuencia de esta última, por la atribución a las municipalidades de un ámbito competencial tan amplio como exija la satisfacción de sus intereses peculiares.

Pieza clave de la organización municipal así concebida es -conforme al pensamiento maurista- el Alcalde. El modelo de Alcaldía que define el Estatuto Municipal está determinado básicamente por las notas de eficacia e independencia de su gestión. De esta forma sus facultades gestoras se incrementan con algunas de nuevo cuño, como la de poder plantear cuestiones de competencia, que ha destacado Lorenzo MARTIN-RETORTILLO (38). Por otra parte se garantiza su independencia mediante su origen electoral -elección por la Corporación de entre los Concejales o de entre los elegibles- y con la supresión de destituciones y suspensiones gubernativas, en lo que a sus competencias propias se refiere. El control político de su gestión pasa a ser ejercido por la propia Corporación y por el electorado, a los que queda atribuida la facultad de destituir al Alcalde. El Ejecutivo del Estado se reserva la posibilidad de suspenderlo en el ejercicio de sus competencias delegadas a través del nuevo instituto de la exoneración, lo que reafirma

(38) MARTIN-RETORTILLO Y BAQUER, L. : "La protección formal de las competencias: La posición de los entes locales en el sistema español de conflictos jurisdiccionales"; en "Descentralización administrativa y organización política"; Tomo II; Alfaguara; Madrid, 1973; pp. 703 y 704. 
la separación entre una y otra parcela de las atribuciones de la Alcaldia. Destacable es también la supresión que hace el Estatuto de la figura del Síndico, con atribución de sus facultades al Alcalde y eventualmente también al segundo Teniente de Alcalde.

Obligado es, sin embargo, señalar la inaplicación del Estatuto en muchos de los citados aspectos, tanto por haberlos dejado en suspenso el propio texto -supuesto del procedimiento de acceso a los cargos concejiles- como por imponerlo de facto, en todo caso, la propia excepcionalidad de la situación política del momento.

\section{EL ALCALDE REPUBLICANO.}

El Alcalde republicano de la Ley de 1935 está muy próximo al del Estatuto, como lo está la Administración Local en su conjunto. En armonía, sin embargo, con la mayor democratización de las estructuras locales que se establece en el nuevo texto, se potencia también el origen democrático del Alcalde: se elige prioritariamente por el electorado entre el propio cuerpo electoral y subsidiariamente por la Corporación entre sus miembros. El paso ha de estimarse trascendente si se recuerda que, con anterioridad, únicamente la Ley de 1840, después de su modificación, y la de 1856, y sólo por vía de sufragio censitario, habian recogido la elección directa del Alcalde. Igualmente se reafirma su condición de órgano local: no es necesariamente delegado del Gobierno, criterio cuyo único antecedente está en la Ley moderada de 1845.

Como dato negativo hay que anotar la posibilidad de suspensión gubernativa del Alcalde, cuando concurran supuestos de supresión de garantías constitucionales -medida explicable por el grave deterioro de la convivencia social del momento, que impone determinados recortes a las concepciones autonomistas del Estatuto- y la aparición nuevamente, y por última vez, de la figura del Síndico, cuyo insistente retorno vuelve a ser expresión de la especial resistencia que ofrecen las instituciones locales a su desaparición.

\section{EL ALCALDE FRANQUISTA.}

El régimen franquista -regulado fundamentalmente por la Ley de Régimen Local de 1955 y el Reglamento de Organización de 1952acuña también su propio modelo de Alcalde. La concepción vertical que de sus estructuras tiene este régimen determina el rasgo más definidor de la citada magistratura: su dependencia existencial del 
Poder central. La libérrima facultad de éste para el cese y la designación de los Alcaldes -en abierta discrepancia con las propias Leyes Fundamentales, después de la aprobación de la Ley Orgánica del Estado y que contó con la oposición de buena parte de la doctrina, representada, entre otros autores, por Cirilo MARTIN RETORTILLO (39)dota al cargo de una esencial inestabilidad, condicionando en modo extremo la gestión del primer mandatario local y neutralizando de consuno, en buena medida, los estrechos márgenes de autonomía que reserva esta Ley a las municipalidades. Pero sobre todo procura al Alcalde una total vinculación al Ejecutivo del Estado y le imprime una especial carga de autoridad, frente a unas Corporaciones elegidas por un artificioso sistema electoral, que supone el rechazo del sufragio universal.

La habitual concurrencia, por otra parte, en el Alcalde franquista de la condición de Jefe Local del Movimiento determina otra paralela vía de subordinación jerárquica, con puntos comunes en la autoridad gubernativa provincial y en la propia cúspide del Estado.

Pero, pese a que este Alcalde ofrece rasgos absolutamente diferenciales en la trayectoria de la Alcaldia hacia su configuración actual, no se interrumpe tampoco en aspectos concretos esa línea evolutiva. En este sentido, la Ley de Régimen Local sigue el criterio de la republicana de 1935 en lo referente a la atribución de las facultades delegadas al Alcalde. Desaparece asimismo definitivamente con este texto la secular figura del Sindicato.

\section{EL ALCALDE DE LA TRANSICION POLITICA.}

A la transición política corresponde la Ley de Bases del Estatuto de Régimen Local de 1975, que tiene como finalidad casi exclusiva el retorno al sufragio universal activo y a la elegibilidad del Alcalde por el sistema de elección indirecta. La permanencia de las Leyes Fundamentales del régimen llevará sin embargo a una artificiosa combinación de sufragio universal activo/sufragio articulado pasivo de muy difícil sustentación, como demostró la propia realidad de los hechos. Por otra parte, el citado origen electivo del Alcalde se ve neutralizado, en buena medida, por el mantenimiento de los persistentes instrumentos de la suspensión y la destitución gubernativas.

En otros aspectos también esta norma se alinea en esa casi ininterrumpida trayectoria del Alcalde que desemboca en el momento

(39) MARTIN RETORTILLO, C. : "Ley de Régimen Local (Texto Refundido de 1955)"; Aguilar; Madrid, 1958; p. 38. 
actual; sólo es representante del Poder central cuando expresamente se le asigne tal atribución; el cargo se hace remunerado y la obligatoriedad del mismo únicamente es ya referible a su ejercicio y no a su aceptación.

$Y$ hasta aquí nuestro Alcalde histórico definido, en un rápido y condensado repaso, por aquellos rasgos que, a nuestro juicio, de una forma u otra, han contribuido a delimitar y modelar al Alcalde actual, de cuyos aspectos más destacables y originales nos ocupamos a continuación.

\section{MODELOS DIFERENCIADOS.}

Marginamos, por razón de espacio, modelos diferenciados: la figura del Corregidor -próximo a los Alcaldes de real nombramiento y al Alcalde franquista, que aparece en el R. D. de 1835 y en la Ley Moderada de 1945; los Alcaldes correspondientes a los regímenes especiales de concejo abierto, máxima expresión de la democracia local, que por primera vez regula el Estatuto Municipal; y de gobierno por Comisión y por Gerente, que asimismo crea el texto de la Dictadura conforme a modelos extranjeros y en los que prevalece el criterio de concentración de poder y autoridad y se agudiza el sentido de eficacia de que está penetrado dicho Código (40); el Alcalde catalán de la Ley de 1933 y 1934, muy cercano al texto de 1924 y a la propia Ley Municipal de 1935, y que hace posible el Estatuto de Autonomía de Cataluña y, en definitiva, la Constitución republicana de 1931, a partir de la acuñación del concepto de Estado integral, como fórmula intermedia entre el Estado unitario y el Estado federal (41); y los Alcaldes de Madrid y Barcelona regulados por las leyes Especiales de los respectivos municipios (42) al amparo del art, 94. 2 de la Ley de Régimen Local, en los que predomina asimismo el sentido gerencial de la Alcaldía, y cuya vigencia mantiene la actual Ley Reguladora de las Bases del Régimen Local (43) y, en su respectivo caso, la Ley Municipal y de Régimen Local de Cataluña (44).

(40) Hay que destacar, sin embargo, la nula aplicación práctica de estas figuras.

(41) JIMENEZ ASUA, Presidente de la Comisión dictaminadora del texto constitucional defendería esta expresión afirmando estar en crisis todo lo referente a la antítesis Estado federal y Estado unitario (Diario de Sesiones del Congreso; núm. 28, 27. 8. 1931; pp. 644-645).

(42) El Texto articulado de la Ley Especial del Municipio de Madrid se aprueba por Decreto 1674/1963, de 11 de julio, modificado por Decreto 2482/1970, de 22 de Agosto. El Texto articulado de la Ley Especial del Municipio de Barcelona se aprueba por Decreto 1166/1960, de 15 de junio.

(43) Salvo en lo que se oponga, contradiga o resulte incompatible con esta Ley (Disposición adicional sexta).

(44) Disposición transitoria primera y artículo 75. 


\section{EL ALCALDE ACTUAL.}

Encarado el Alcalde actual desde la perspectiva histórica que hemos venido analizando, la primera afirmación válida es la de que la Alcaldía definida fundamentalmente por la Ley Reguladora de las $\mathrm{Ba}$ ses del Régimen Local y por la Ley Orgánica del Régimen General Electoral, ambas de 1985, y desde luego por la Constitución de 1978, se alinea junto a los modelos conformados por aquellas normas que han postulado derechos y libertades para los municipios. Esta posición viene marcada esencialmente por el régimen de autonomía de la Administración municipal, en el que el Alcalde se inserta, y que está definido, a su vez, por el origen democrático de todas las magistraturas locales, la ausencia de toda dependencia jerárquica o tutelar de otras Administraciones, la asignación de un ámbito competencial propio, la atribución de poder de autonormación, y la disponibilidad de recursos económicos suficientes para el cumplimiento de sus fines.

Por otra parte, el modelo representa el final del proceso de decantación de la figura, según hemos venido analizando: el Alcalde es un órgano netamente local y representativo del Ayuntamiento y, en tal sentido, su ámbito competencial se define en toda su cobertura como propio, tanto si sus facultades le están atribuidas por leyes municipales como si lo hacen leyes sectoriales.

Desaparecidas las arcaicas figuras de los Alcaldes distintos del "Primero", del Procurador del Común (45) y del Síndico que, en el pasado, disputaron parcelas de poder al Alcalde, sólo ha subsistido, como cargo diferenciado al de Concejal, el de Teniente de Alcalde; y el de Alcalde de Barrio, como institución extracorporativa. Asimismo ambas magistraturas, después de diversos ensayos de configuración que, en algunos momentos, le otorgaron facultades propias, han venido a constituirse definitivamente en órganos auxiliares y delegados de éste, en una clara situación de dependencia (46).

El carácter del cargo se encuentra igualmente al término del proceso de su transformación desde su inicial consideración de obligatorio y gratuito al de su configuración como voluntario y remunerado, cuando se ejerza con exclusividad. La posibilidad de renuncia, sin ninguna limitación, da plena virtualidad al primero de dichos caracteres;

(45) En el Real Decreto de 1835 la institución del Sindico se ve sustituida por la del Procurador del Común.

(46) Contrariamente al criterio de la legislación general (Real Decreto Legislativo 781/1986, de 18 de Abril, y Reglamento de Organización, Funcionamiento y Régimen Juridico de las Corporaciones Locales aprobado por Real Decreto 2568/1986, de 28 de Noviembre), la ley de Régimen Local de la Región de Murcia 6/1988, de 25 de Agosto, sí atribuye facultades propias al Alcalde de Barrio (artículo 38). 
al tiempo que el segundo se reafirma y complementa con las paralelas obligaciones mutuales que se imponen a la Corporación y que homologan, a estos efectos, los cargos municipales a los derivados de una relación de empleo; con lo que se llega, en tal aspecto, al extremo opuesto de la regulación de la Constitución de Cádiz, con idéntica finalidad: hacer extensivos los oficios concejiles a todos los ciudadanos. Este cambio supone, por otro lado, una alteración de especial significación en la configuración de la Alcaldía, si se tiene en cuenta que la remuneración del cargo históricamente ha constituido uno de los datos que han marcado las diferencias entre las figuras del Alcalde y del Corregidor (47).

Junto a ello, la Alcaldía actual se delimita con aportes de, prácticamente, la totalidad de los textos legales que en el pasado han regulado esta magistratura. En su origen electivo y en la supresión de los institutos de la suspensión y de la destitución gubernativas se recoge la tradición progresista. Incluso el procedimiento establecido para la disolución de la Corporación en su conjunto, por gestión gravemente dañosa a los intereses generales, se aproxima al de la ley de 1856, dada la particular significación que en aquél tiene la intervención del Senado; y ello abstracción hecha de la critica desfavorable que merece el mantenimiento de este instrumento en lo que representa de grave atentado a la autonomia municipal.

La concepción democrática del Alcalde, al igual que la del resto de magistraturas locales, enlaza evidentemente con la Constitución de Cádiz y con las Leyes Municipal y Electoral de 1870 y, sobre todo, con la republicana de 1935; en tanto que el sistema de representación proporcional y las candidaturas de lista cerrada ya fueron establecidos por el Estatuto Municipal, si bien regidos por reglas distintas (48).

Se siguen los criterios moderados en la supresión de obstáculos a la reelección de todos los cargos concejiles, superándose el sistema de "huecos", típico de nuestras leyes progresistas. Igual doctrina se adopta en cuanto a la mayor duración del mandato respecto de las citadas leyes -al menos en un primer momento-, en beneficio de la eficacia de la gestión.

El control político del Alcalde, que se atribuye a la Corporación, tiene su indudable antecedente en el Código de la Dictadura y en la Ley republicana.

(47) V. MORILLO-VELARDE PEREZ, J. I. : "El Alcalde en la Administración Española"; Instituto Garcia Oviedo; Sevilla, 1977.

(48) El Estatuto Municipal de entrada a un sistema de representación proporcional tomado del método Andrade y Hare, adoptado por primera vez en Europa en la Ley danesa de 2. 10. 1855. 
Finalmente, la asignación al Alcalde de las facultades no atribuidas expresamente a otros órganos municipales, por via de cláusula residual, ya se establecía en la Ley de Régimen Local de 1955, tratándose además de una solución que viene exigida, en todo caso, por el carácter monocrático de la Alcaldía y por su condición de órgano ejecutivo y de gestión.

Quizás los aspectos más novedosos de la regulación del actual Alcalde -además de los ya citados sobre el carácter del cargo- se encuentren en el sistema de acceso al mismo -si exceptuamos el precedente de la Ley de Elecciones Locales de 1978- a partir de la doble fórmula establecida por la Ley Electoral, una principal e indirecta -la elección por la Corporación entre los Concejales cabezas de lista-; y otra subsidiaria y directa -la atribución de la Alcaldia al primer Concejal de la lista más votada-, a cuyo criterio hay que asignarle, por exigencia constitucional, valor de elección popular del Alcalde (49).

Asimismo, la moción de censura -estudiada, entre otros autores, por LOPEZ PELLICER (50)- también tiene un tratamiento original, sobre todo a partir del carácter constructivo con que se concibe y cuya única referencia anterior hay que encontrarla en la regulación que de esta misma institución se contiene en nuestro texto constitucional, en relación con el Presidente del Gobierno de la Nación.

Sin embargo, el rasgo que con más insistencia se ha destacado como definidor del Alcalde actual ha sido el de su mayor fortaleza respecto de modelos anteriores, sobre la base de la independencia de su gestión -al insertarse en un régimen de autonomía municipal- y de las supuestas mayores facultades que se le asignan. Pero, contrariamente, habría que señalar que la autonomía predicable del ente municipal en su conjunto no alcanza en igual medida al Alcalde en sus relaciones interorgánicas -máxime cuando no disponga de la mayoría absoluta para gobernar-, a partir de los amplios márgenes con que se regula la moción de censura. Al propio tiempo, los criterios de asignación de facultades a esta magistratura no varían excesivamente de los de la legislación anterior, de donde incluso, como acabamos de señalar, se toma la referida cláusula residual.

En todo caso, lo que sí permanece constante, por responder a aspectos sociológicos y a motivaciones metajurídicas, es el sentido que el Alcalde tiene en la conciencia colectiva de magistratura natural de la comunidad vecinal, de autoridad local necesaria e insustituible y de

(49) V. al respecto Diario de Sesiones de la Comisión de Interior; núm. 20, 22. 2. 1978; p. 709.

(50) LOPEZ PELLICER, J. A.: "La moción de censura al Alcalde"; Revista de la Administración Local y Autonómica; núm. 247, 1990; pp. 433-448. 
instancia inmediata y espontánea del ciudadano. Todo ello dota a la Alcaldía de un interés de primera magnitud -ni siquiera eclipsado en aquellos momentos en que se fuerza la despolitización de la figura desde el sistema político configurador del Estado- y la convierte en una institución universal y permanente. 
